\title{
MODELO COMPETITIVO DA DISTÂNCIA PERCORRIDA POR FUTEBOLISTAS NA UEFA EURO 2008*
}

\author{
MS. TIAGO VOLPI BRAZ \\ Mestre em educação física - Unimep \\ Professor horista do Departamento de Educação Física, Faculdade de Americana (São Paulo - Brasil) \\ E-mail: tiagovolpi@yahoo.com.br
}

\author{
MS. LEANDRO MATEUS PAGOTO SPIGOLON \\ Mestre em educação física - Unimep \\ Professor horista do Departamento de Educação Física, Faculdade de Vinhedo (São Paulo - Brasil) \\ E-mail: leandro_edfisica@hotmail.com
}

\author{
GRAD. NATHÁLIA ARNOSTI VIEIRA \\ Graduada em educação física \\ Unimep (São Paulo - Brasil) \\ E-mail: nathaliaarnosti@gmail.com
}

\section{DR. JOÃO PAULO BORIN}

Doutor em educação física - Unicamp

Professor adjunto do Departamento de Ciências do Esporte, Unicamp -

Campus Limeira (São Paulo - Brasil)

E-mail: joao.borin@fca.unicamp.br

\begin{abstract}
RESUMO
O objetivo do presente estudo centra-se em conhecer o modelo competitivo da distância percorrida por futebolistas na Uefa Euro 2008, mediante as posições de jogo, os tempos e a distância total percorrida durante as partidas. Foram analisadas todas as partidas das 16 seleções, totalizando 31 jogos, dos quais participaram 460 futebolistas. Posteriormente, produziram-se informações descritivas e inferenciais. Os principais resultados apontam que: i) futebolistas da elite europeia percorreram $10232 \pm 852 \mathrm{~m}$; ii) meio-campistas ( 10894 $\pm 648 \mathrm{~m}$ ) percorreram maior distância, seguidos pelos laterais ( $10274 \pm 694 \mathrm{~m})$, atacantes ( $10108 \pm 624 m)$, zagueiros (9498 $\pm 592 \mathrm{~m})$ e goleiros (4198 $\pm 610 \mathrm{~m})$; iii) a distância média percorrida no $1^{\circ}$ tempo $\left(4907 \pm 20 \mathrm{~lm}\right.$ ) das partidas foi maior do que a do $2^{\circ}$ tempo $(4890 \pm 238 \mathrm{~m})$.
\end{abstract}

PALAVRAS-CHAVE: Modelos competitivos; distância percorrida; futebol.

* O presente trabalho não contou com apoio financeiro de nenhuma natureza para sua realização. Não houve conflitos de interesses para realização do presente estudo. 
Conhecer as peculiaridades das modalidades diante da competição tem-se tornado importante para a correta prescrição dos treinamentos e a melhoria do desempenho desportivo. Tal premissa vem sendo direcionada pela elaboração de modelos gerais, de grupo e individuais da atividade competitiva e do preparo em concordância com as particularidades de cada desportista.

Precisamente, os modelos competitivos gerais refletem a característica do objeto ou processo em concordância com dados de grupos relativamente grandes de desportistas que possuem perfis semelhantes; em contrapartida, os modelos competitivos de grupo são construídos com base no estudo de um conjunto concreto de atletas ou equipes, marcados por sinais específicos dentro dos limites de determinada modalidade; já os modelos competitivos individuais são elaborados separadamente para cada desportista, baseando-se nos dados de pesquisas individuais sobre a estrutura da atividade competitiva (PLATONOV, 2008). Na formação desses modelos, destacam-se as características da atividade competitiva importantes para a modalidade praticada, de modo que estes dirigem a atenção aos aspectos críticos de dados que conduzem ao sucesso desportivo, permitindo o conhecimento de padrões de jogo das modalidades, caracterização dos desportistas e comparações individuais, setoriais e coletivas (NEVILL; ATKINSON; HUGHES, 2008).

Mediante sua crescente importância, tais termos foram introduzidos na prática desportiva, já que, há tempos, vêm sendo citados juntamente com suas derivações, com uma frequência vinte vezes maior do que acontecia no final das décadas de 1960 e 1970 (Platonov, 2008). Garganta (200 I) aponta para o aumento de estudos científicos realizados em diversas modalidades com intuito de formar modelos competitivos, fato que permite perceber a enorme expressão que tais desígnios assumem no quadro da investigação aplicada ao desporto. Especificamente no futebol, Reilly e Gilbourne (2003) revelaram que a distribuição de comunicações realizadas nos quatro primeiros Congressos Mundiais da modalidade, publicados no Journal of Sport Science, confirmam o interesse na análise competitiva, sendo o principal assunto abordado: 5 I dos 296 estudos relacionavam-se a tal problemática.

Por conseguinte, a investigação das ações competitivas no futebol é, atualmente, uma das bases do processo de preparação para o desempenho na modalidade (ZUBILLAGA et al., 2007), provendo informações úteis sobre a performance dos futebolistas, que podem ser usadas para planejar períodos de treinamento ou avaliá-los na própria competição (BARROs et al., 2007). Subsídios sobre tipo, inten- 
sidade, volume, efetividade e frequência de ações competitivas têm um significado importante ao entendimento das características físicas, técnicas, táticas e estratégicas dos futebolistas (SHEPARD, 1999), principalmente na elite da modalidade (DI SALVO; Baron; Cardinale, 2007).

Nessa linha, a distância percorrida por futebolistas durante as partidas tem sido amplamente investigada (RellLy; ThOMAS, 1976; MIYAGI; OHASHI; KITAGAWA, 1999; Hennig; Briehle, 2000; Barros et al., 2007; Di Salvo; Baron; Cardinale, 2007; RampininI et al., 2007; Randers; Jensen; Krustrup, 2007; Zubillaga et al., 2007), principalmente sobre a perspectiva das diferenças entre as posições de jogo (DI Salvo et al., 2007), dos tempos das partidas (Mohr; Krustrup; BangSBO, 2003) e da distância total percorrida por futebolistas em determinadas competições (ODETOYINBO; Wooster; LANE, 2007), direcionamentos estes considerados no delineamento do presente estudo. Recentemente, Di Salvo, Baron e Cardinale (2007) criaram modelos competitivos gerais da intensidade e distância percorrida por 79| futebolistas em 68 partidas do continente europeu; Rampinini et al. (2007) investigaram modelos das ações competitivas de uma mesma equipe mediante o confronto com equipes de maior e menor nível competitivo; Barros et al. (2007) buscaram modelos competitivos de grupo para futebolistas profissionais em competições brasileiras e Di Salvo et al. (2007) focaram a análise das funções táticas exercidas pelos futebolistas no que concerne a distância total percorrida, diferença entre os tempos, tipos e intensidade das ações ocorridas no jogo.

Seguindo tal contexto, é notório o interesse em investigar futebolistas durante sua atividade competitiva, a fim de criar modelos competitivos gerais, de grupo e individuais que contribuam para: i) o entendimento do jogo; ii) o aperfeiçoamento e monitoramento do desempenho competitivo; e iii) a apropriada prescrição dos meios e métodos de treinamento específicos a modalidade baseados nessas informações. Sendo assim, o objetivo do presente estudo centra-se em conhecer o modelo competitivo da distância percorrida por futebolistas na Uefa Euro 2008, mediante as posições de jogo, os tempos e a distância total percorrida durante as partidas.

\section{METODOLOGIA}

\section{BASE DE DADOS}

Os dados para o estudo foram obtidos no website oficial da Uefa Euro 2008 (http://www.euro2008.uefa.com). Foram analisadas todas as partidas das 16 
seleções participantes, totalizando 31 jogos. Em concordância com Rampinini et al. (2007), foram considerados os futebolistas que participavam de todo o tempo das partidas, excluindo os que foram substituídos e os substitutos, totalizando 460 atletas, conforme posição de jogo: goleiros (GO), $n=56$; zagueiros (ZA), $n=120$; laterais (LA), $n=99$; meio-campistas (MC), $n=134$; e atacantes (AT), $\mathrm{n}=51$.

Seguindo procedimentos de outros estudos (DI SALVO et al., 2007; RANDERS; Jensen; KRUSTRUP, 2007), para o modelo geral da distância percorrida nos jogos foram excluídos os goleiros, totalizando assim 404 futebolistas. Em contrapartida, para o modelo competitivo dos tempos das partidas foi considerada a média da distância percorrida pelas seleções nas partidas incluindo os goleiros e os futebolistas substituídos e substitutos, já que os dados do site mencionado eram assim disponibilizados, totalizando uma amostra de 62 equipes, tanto para o $1^{\circ}$ tempo como $2^{\circ}$ tempo de jogo.

\section{CUIDADOS ÉTICOS}

O presente estudo não envolveu experimentação com humanos ou animais, mas foi conduzido em total conformidade com os parâmetros éticos descritos pelo Conselho Nacional de Saúde (BRASIL, 1996). Em consenso com o estudo de Medeiros Filho e Haddad (2008), os dados utilizados para o desenvolvimento deste estudo foram publicados no website mencionado e estão acessíveis a todo e qualquer interessado, de modo que as seleções consideradas para o presente estudo são constantemente expostas a análises de seus rendimentos e têm seus nomes, cotidianamente, veiculados pela mídia impressa, televisiva e radiofônica.

\section{TRATAMENTO ESTATÍSTICO}

Os dados foram armazenados no software BioEstat 5.0 e, a seguir, produziramse informações no plano descritivo por meio de estatística descritiva (mínimo, máximo, amplitude total, mediana, primeiro e terceiro quartil, média aritmética, desvio padrão e coeficiente de variação).

No plano inferencial, foi utilizado o teste Anova one-way para análise de medidas repetidas entre as posições de jogo e tempo das partidas, seguido pelo post hoc de Tukey para comparações múltiplas quando necessário, adotando-se nível de significância de 1\%. 


\section{RESULTADOS}

Optou-se por produzir informações tabulares com medidas descritivas dos modelos competitivos de grupo das posições de jogo e tempos dos jogos, bem como se considerou o modelo geral da distância percorrida pelos futebolistas em todas as partidas realizadas.

Dessa forma, na tabela I são apresentadas medidas descritivas do modelo competitivo conforme posições de jogo e do modelo geral da distância percorrida por futebolistas na Uefa Euro 2008.

Tabela I: Medidas descritivas da distância percorrida (m) por futebolistas na Uefa Euro 2008

\begin{tabular}{lllllll}
\hline Estatística descritiva & Goleiros & Zagueiros & Laterais & Meio-campistas & Atacantes & Total \\
\hline \hline $\mathrm{n}=$ (futebolistas) & 56 & 120 & 99 & 134 & 51 & 404 \\
Mínimo & 2960 & 7650 & 8740 & 9540 & 8650 & 7650 \\
Máximo & 5350 & 11310 & 12240 & 12740 & 11510 & 12740 \\
Amplitude total & 2390 & 3660 & 3500 & 3200 & 2860 & 5090 \\
Mediana & 4195 & 9535 & 10260 & 10955 & 10180 & 10190 \\
Primeiro quartil (25\%) & 3840 & 9098 & 9875 & 10423 & 9745 & 9628 \\
Terceiro quartil (75\%) & 4663 & 9845 & 10670 & 11358 & 10495 & 10855 \\
Média aritmética & 4198 & 9498 & 10274 & 10905 & 10108 & 10232 \\
Desvio padrão & 610 & 592 & 694 & 659 & 624 & 852 \\
Coeficiente de variação & $14,5 \%$ & $6,2 \%$ & $6,7 \%$ & $6,1 \%$ & $6,2 \%$ & $8,3 \%$ \\
\hline
\end{tabular}

Notoriamente, os resultados variaram entre futebolistas de mesma posição de jogo (GO, entre 2960 e 5350m; ZA, entre 7650 e II 3 I Om; LA, entre 8740 e I2240m; MC, entre 9540 e 12740m; e AT, entre 8650 e II 5 IOm). Em contrapartida, o modelo competitivo geral da distância percorrida por futebolistas na Uefa Euro 2008 foi de $10232 \pm 852$ metros (Tabela I).

O resultado da Anova one-way para medidas repetidas demonstrou que as distâncias percorridas pelas distintas posições de jogo são significativamente diferentes (Figura I). 


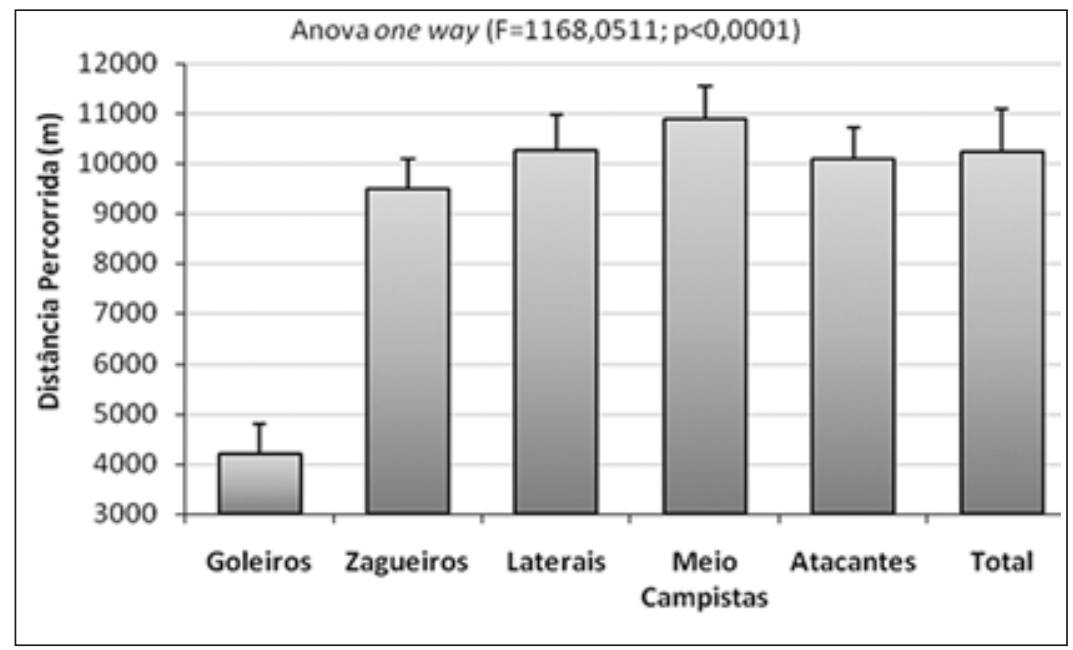

Figura I: Valores médios e desvio padrão da distância percorrida pelas posições de jogo na Uefa Euro 2008, bem como o resultado do teste Anova one-way para medidas repetidas.

Posteriormente, com objetivo de identificar em quais posições ocorreram tais diferenças, realizou-se o teste post hoc de Tukey, conforme resultados da tabela 2.

Tabela 2: Diferença entre médias do modelo da distância percorrida por futebolistas divididos por posição de jogo na Uefa Euro 2008

\begin{tabular}{|l|c|c|c|}
\hline Post hoc de Tukey: & Diferença da distância percorrida $(\mathrm{m})$ & $\mathrm{Q}$ & $(\mathrm{p})$ \\
\hline Goleiros e zagueiros & 5300 & $72.305 \mathrm{I}$ & $<0.0$ I \\
\hline Goleiros e laterais & 6076 & 80.2248 & $<0.01$ \\
\hline Goleiros e meio-campistas & 6707 & 93.0658 & $<0.01$ \\
\hline Goleiros e atacantes & 5910 & $67.408 \mathrm{I}$ & $<0.0 \mathrm{I}$ \\
\hline Zagueiros e laterais & 776 & 12.6142 & $<0.01$ \\
\hline Zagueiros e meio-campistas & 1407 & 24.7239 & $<0.01$ \\
\hline Zagueiros e atacantes & 610 & 8.052 & $<0.01$ \\
\hline \hline Laterais e meio-campistas & 632 & 10.5237 & $<0.01$ \\
\hline Laterais e atacantes & 166 & 2.1276 & $\mathrm{~ns}$ \\
\hline Meio-campistas e atacantes & 798 & 10.7056 & $<0.01$ \\
\hline
\end{tabular}

Encontraram-se diferenças significativas $(p<0,01)$ entre todas as posições de jogo, exceto para a comparação entre LA e AT (Tabela 2). O grupo GO percorreu menor distância quando comparado com os demais grupos; já o de 
ZA percorreu menor distância que os grupos LA, MC e AT; o grupo MC percorreu maior distância nos jogos que o de LA e AT, e o grupo LA apresentou valores maiores do que o AT (Tabela 2).

Quanto ao tempo das partidas, o $1^{\circ}$ tempo apresentou valores médios maiores do que o $2^{\circ}$ tempo de jogo (0,4\%), no entanto, sem significância estatística. Assim, o modelo competitivo geral da distância percorrida no $1{ }^{\circ}$ tempo das partidas na Uefa Euro 2008 foi de $4907 \pm 201$ metros e do $2^{\circ}$ tempo, de $4890 \pm 238$ metros, conforme demonstra a tabela 3.

Tabela 3: Medidas descritivas da distância percorrida por futebolistas entre os tempos dos jogos na Uefa Euro 2008.

\begin{tabular}{|c|c|c|}
\hline Estatística descritiva & $1^{\circ}$ tempo $(\mathrm{m})$ & $2^{\circ}$ tempo $(\mathrm{m})$ \\
\hline $\mathrm{N}=$ (equipes) & 62 & 62 \\
\hline Mínimo & 4176 & 3955 \\
\hline Máximo & 5348 & 5324 \\
\hline Amplitude total & 1172 & 1369 \\
\hline Mediana & 4938 & 4916 \\
\hline Primeiro quartil (25\%) & 4843 & $479 \mid$ \\
\hline Terceiro quartil (75\%) & 5020 & 5056 \\
\hline Média aritmética & 4907 & 4890 \\
\hline Desvio padrão & 201 & 238 \\
\hline Coeficiente de variação & $4,1 \%$ & $4,8 \%$ \\
\hline
\end{tabular}

\section{DISCUSSÃO}

Os resultados encontrados para a distância percorrida (I $0232 \pm 852 \mathrm{~m})$ por futebolistas na Uefa Euro 2008 aproximam-se dos valores relatados por outras pesquisas. Mohr, Krustrup e Bangsbo (2003) apresentaram valores de $10330 \pm$ $260 \mathrm{~m}$ para 24 futebolistas profissionais da Dinamarca. De acordo com Randers, Jensen e Krustrup (2007), futebolistas profissionais da Suécia $(n=23)$ percorreram $10150 \pm 210 \mathrm{~m}$ em partidas nacionais e internacionais. Na Inglaterra, foram relatados valores de $10274 \pm 609 \mathrm{~m}$ para 12 futebolistas profissionais (THATCHER; BATTERHAM, 2004). Na final da Liga dos Campeões da Europa de 2006, Zubillaga et al. (2007) encontraram valores de $10339 \mathrm{~m}$ a I0549m para as equipes analisadas.

Da mesma forma, Barros et al. (2007) verificaram que a distância percorrida por 55 futebolistas profissionais do Brasil foi de $10012 \pm 1024 \mathrm{~m}$. Recentemente, Bradley et al. (2009) apresentaram resultados de $10714 \pm 991 \mathrm{~m}$ para 374 jogadores da elite da Inglaterra. Em consequência desses apontamentos, parece que a distância total percorrida por futebolistas profissionais se situa entre 10000 e I I 000 
metros. De fato, após uma breve revisão de literatura, Braz (2009) verificou que, em estudos recentes (2004 a 2009), jogadores profissionais apresentam valores entre $10012 \mathrm{~m}$ e $11393 \mathrm{~m}$.

Cabe destacar que a distância percorrida durante os jogos ocorre principalmente em deslocamentos de baixa intensidade (0- I I km/h), normalmente de 5526 a 703 Im (BARROS et al., 2007; Dı SAlvo et al., 2007). A distância percorrida em intensidades de 11 - $14 \mathrm{~km} / \mathrm{h}$ é $1600 \mathrm{~m}$ e $1654 \mathrm{~m}$, $14-19 \mathrm{~km} / \mathrm{h}$ é $1721 \mathrm{~m}$ e $1759 \mathrm{~m}$, $19-23 \mathrm{~km} / \mathrm{h}$ é $691 \mathrm{~m}$ e $605 \mathrm{~m},>23 \mathrm{~km} / \mathrm{h}$ é $437 \mathrm{~m}$ e $337 \mathrm{~m}$, valores correspondentes a futebolistas brasileiros (BARROs et al., 2007) e de futebolistas que atuavam na elite da Espanha (Dı SALVo et al., 2007), respectivamente. Os futebolistas realizam apenas 2\% de deslocamentos com bola, I $1 \%$ em forma de sprints (média de uma ação a cada 90 segundos), 20\% em corridas de moderada a alta intensidade, 36\% trotando, 24\% andando e 7\% em deslocamentos de costas (ReILLY; THOMAS, 1976).

Contudo, há necessidade de destacar alguns fatores que podem influenciar os resultados da variável dependente do presente estudo. O modelo competitivo da distância percorrida por futebolistas durante as partidas depende da posição de jogo (DI SALVO et al., 2007), do estilo da equipe (RIENZI et al., 2000), do nível competitivo (Mohr; Krustrup; BAngsbo, 2003), do tipo de competição (Reilly, 2005), da condição física dos futebolistas (Dı SALVO et al., 2007), do espaço da competição (Shepard, 1999), da evolução da modalidade (STRUdWiCK; Reilly, 200 I) e dos diferentes momentos da temporada (RAMPININI et al., 2007).

O estilo e o nível competitivo das equipes são fatores que estão ligados ao componente técnico-tático do desempenho na modalidade. A atividade competitiva dos futebolistas e das equipes está associada à imprevisibilidade e complexidade das ações/acontecimentos do jogo, sempre em decorrência das relações de cooperação e de oposição, ocorrida em um contexto aleatório, influenciado e determinado pelas sucessivas configurações que o jogo vai apresentando (GARGANTA, 200 I). Dessa forma, a distância percorrida pelos jogadores dependerá da interação com o adversário, de seus companheiros de equipe e dos acontecimentos sucessivos do jogo. Por isso, em determinadas partidas, podem ser encontrados resultados não condizentes com o modelo ( $0232 \pm 852 \mathrm{~m}$ ) apresentado neste estudo para futebolistas de elite da Europa, já que as condições decorrentes dos jogos são diferentes, principalmente em relação ao nível competitivo das equipes, da estratégia e dos sistemas táticos utilizados.

Entretanto, cabe destacar que os modelos competitivos elaborados a partir de um grande número de desportistas, como é o caso do presente estudo $(n=404)$, refletem características generalizadas da modalidade (PLATONOV, 2008), tendo sua importância para a prescrição dos treinamentos. Tal premissa é evidenciada quando 
comparada a distância percorrida por futebolistas profissionais de diferentes nacionalidades. O modelo da distância percorrida por jogadores da Uefa Euro 2008 aproxima-se dos valores apresentados para futebolistas brasileiros (BARROs et al., 2007), japoneses (Myagl; OHASHI; Kitagawa, 1999), ingleses (Thatcher; Batterham, 2004), dinamarqueses e suecos (RANDERs; Jensen; KRUstrup, 2007).

Além disso, era de esperar que a condição física dos futebolistas interferisse na distância percorrida durante os jogos. Acerca disso, Mohr, Krustrup e Bangsbo(2003) notaram diferenças entre o final ( $10720 \pm$ I30m), o meio (I0340 $\pm 210 \mathrm{~m}$ ) e o início ( $10130 \pm 350 \mathrm{~m})$ de um macrociclo de preparação de uma equipe dinamarquesa. Rampinini et al. (2007) apontaram valores de $10617 \pm 769 \mathrm{~m}$ para o início, 10827 $\pm 616 \mathrm{~m}$ para o meio e $10921 \pm 753 \mathrm{~m}$ para o fim da temporada. Mohr, Krustrup e Bangsbo (2003) associam esses resultados à melhoria do desempenho durante a temporada, mediado pelo maior número de jogos durante o início (dois por semana) em consequência do fim da temporada (um por semana), interferindo diretamente na organização e estruturação dos ciclos semanais de treinamento.

Os futebolistas da Uefa Euro 2008 iniciavam novo ciclo de treinamento em suas seleções para a preparação da competição em questão. No entanto, tal sistematização vinha acometida pelas particularidades das cargas impostas anteriormente em seus clubes, o que poderia refletir no comportamento competitivo desses desportistas, incidindo nos valores da variável controlada neste estudo. Nessa linha, Helgerud et al. (200 I) mostraram que oito semanas de treinamento sistematizado no futebol, por meio do método intervalado, resultaram em aumento da distância percorrida nos jogos (pré-treino, $8619 \pm$ 1237m e pós-treino, $10335 \pm 1608 \mathrm{~m}$ ). Impellizzeri et al. (2006) compararam os efeitos produzidos por meios gerais e especiais de preparação na distância percorrida por futebolistas juniores nas partidas (meios gerais - pré-treino $9330 \pm 425 \mathrm{~m}$, metade do período de treinos $9958 \pm$ $330 \mathrm{~m}$ e pós-treino $9924 \pm 33 \mathrm{Im}$; meios especiais - pré-treino $9527 \pm 444 \mathrm{~m}$, metade do período de treinos $10036 \pm 510 \mathrm{~m}$ e pós-treino $9926 \pm 404 \mathrm{~m}$ ). Tais pressupostos confirmam a influência da sistematização das cargas de treinamento para a variável controlada no presente estudo.

A própria tendência evolutiva da modalidade interfere nos modelos competitivos elaborados. Strudwick e Reilly (200I) referem que futebolistas analisados em temporadas da elite inglesa (1998/1999 e 1999/2000) percorreram aproximadamente $1500 \mathrm{~m}$ a mais que os futebolistas do início da década de 1990 da mesma liga. Atualmente, relaciona-se tal evolução à intensidade com a qual os futebolistas realizam as ações durante o jogo (Mohr; Krustrup; BangsBo, 2003; DI Salvo et al., 2007), já que, nos últimos anos, não se tem observado diferenças na distância percorrida durante as partidas (ODETOYINBO; WoOster; LANE, 2007; RAMPININI et 
al., 2007). Nessa linha, Di Salvo et al. (2009) demonstraram aumento gradativo na distância percorrida em forma de sprints durante três temporadas (2003/2004, 2004/2005, 2005/2006) da Premier League da Inglaterra.

Outro fator que pode estar atrelado a possíveis diferenças na distância percorrida das partidas são as distintas metodologias empregadas para a análise do jogo (GARGANTA, 200 I). Na literatura, são mencionados diferentes métodos de análise (ReIlly, 2005): análise manual (Reilly; THOMAS, 1976), trigonometria, filmagens com diferentes números de câmeras (DI SALVO et al., 2007), tracking computacional (Misuta, 2005), sistema global de posicionamento GPS (HENNIG; BRIEHLE, 2000) e diferentes softwares para análise de filmagens como Amysco ${ }^{\circledR}$ (ZUBILLAGA et al., 2007), Prozone ${ }^{\circledR}$ (Dı Salvo et al., 2007), Dvideow ${ }^{\circledR}$ (Barros et al., 2007), Tacto ${ }^{\circledR}$ (Caixinha; Sampalo; Mil-Homens, 2004) - fato que deve ser considerado para o diagnóstico dos resultados no que concerne às ações competitivas. Como evidência desse direcionamento, Caixinha, Sampaio e Mil-Homens (2004) mencionaram valores de $14385 \mathrm{~m}$ para futebolistas juniores, diferentemente dos comumente encontrados na literatura (BarRos et al., 2007; DI Salvo et al., 2007; RANDERS; JeNSEN; KRUSTRUP, 2007; ZUBILlaGA et al., 2007) e no presente estudo (Tabela I).

Ao mesmo tempo, foram verificadas diferenças significativas entre os modelos das posições de jogo (Figura I). Meio-campistas percorrem maior distância durante as partidas do que outras posições de jogo (Reilly; ThomAs, 1976; StrudWiCK; ReIllLY, 200 I; Mohr; Krustrup; Bangsbo, 2003; Di Salvo, Baron, Cardinale, 2007; DI SALVO et al., 2007; RAMPININI et al., 2007), fato também sustentado pelo presente estudo (Tabelas I e 2). Isso pode ser explicado principalmente pelas funções táticas exercidas pelas posições de jogo, já que os meio-campistas se caracterizam por ações de transição entre ataque e defesa (CAIXINHA; SAmpalO; MIL-Homens, 2004), ou mesmo pela quantidade de ações competitivas desenvolvidas a baixa intensidade por esses jogadores (REILLY, 2005), pelo próprio direcionamento tático dado pelo treinador (DI SALVO et al., 2007), pela necessidade da posição, que exige maiores movimentações (CAIXINHA; SAMPAIO; MIL-Homens, 2004), ou, ainda, por capacidade aeróbia superior à dos futebolistas de outras posições (SHEPARD, 1999).

Corroborando com os achados do presente estudo (Tabelas I e 2), algumas pesquisas indicam que laterais tendem a percorrer maiores distâncias nos jogos do que atacantes e zagueiros (HenniG; Briehle, 2000; Barros et al., 2007; Di Salvo et al., 2007). Comumente, zagueiros e atacantes apresentam maior volume de deslocamento em curta distância do que outras posições, contribuindo para tal ocorrência (MoHR; KRUSTRUP; BANGSBO, 2003). Todavia, outros autores encontraram valores maiores para atacantes em relação a laterais (REILLY; THOMAS, I976; BANGSBO; NorReGAard; THORSO, 1991). 
Os goleiros apresentam os menores valores para a distância percorrida durante as partidas do que as demais posições de jogo (REIlly; THOMAS, 1976; MisUTA, 2005), fato confirmado no presente estudo (Figura I). O tempo que os goleiros ficam estáticos durante os jogos é aclaradamente maior que o das demais posições, tanto que seu modelo competitivo de atuação preconiza esforços anaeróbios de curta duração (Rellly; THOMAs, 1976). Talvez seja por isso o fato de poucas pesquisas abordarem o modelo competitivo da distância percorrida para goleiros, já que não é uma variável determinante para a posição. Entretanto, o modelo da distância percorrida por goleiros na Uefa Euro 2008, 4198 metros (Tabela I), aproxima-se dos achados de Reilly e Thomas (1976), 3972 metros, e ambos são menores dos que encontrados por Di Salvo et al. (2008), 561 I $\pm 613 \mathrm{~m}$, mas são maiores que os encontrados em competições brasileiras (MISUTA, 2005), 2750 metros, talvez pelo restrito número de sujeitos desse estudo.

Em relação à distância percorrida entre os tempos das partidas, foi verificado decréscimo de $0,4 \%$ do $1^{\circ}$ para o $2^{\circ}$ tempo das partidas na Uefa Euro 2008. Cabe destacar que a fadiga no futebol pode manifestar-se como a deterioração das ações dos futebolistas até o final da partida (REILly, 2005). Essa parece ser uma relação importante a ser considerada no âmbito da modalidade, por isso a importância em se criarem modelos competitivos que preconizem os distintos tempos dos jogos. Por conseguinte, está consolidado na literatura que futebolistas percorrem maior distância no primeiro tempo em consequência do segundo tempo de jogo (MoHR; KrUstrup; BANGSBO, 2003; Barros et al., 2007; DI SAlvo et al., 2007), corroborando a tendência apresentada por futebolistas da Uefa Euro 2008 (Tabela 3).

É importante considerar que a fadiga ocasionada entre os tempos dos jogos se evidencia em três momentos: i) posteriormente a ações intensas em curto período de tempo, ii) na fase inicial do $2^{\circ}$ tempo e iii) próximo ao final das partidas (BANGSBO; MOHR; KRUSTRUP, 2006). BARROs et al. (2007) reportaram que $93 \%$ dos 55 futebolistas brasileiros analisados percorreram maiores distâncias no tempo inicial das partidas. Tal diferença evidenciou-se especificamente a partir do oitavo minuto da etapa final de jogo. Outras pesquisas não ratificaram diferenças em futebolistas europeus no que concerne à análise sequencial dos minutos perante a distância percorrida entre os tempos de jogo, todavia apontam que a performance dos futebolistas diminui no segundo tempo de jogo, especialmente nos 15 minutos finais (MOHR; KRUSTRUP; BANGSBO, 2003). Dessa forma, o modelo da distância percorrida por futebolistas difere entre os tempos dos jogos, seja em proporções menores $(0,4 \%)$ como notificado para futebolistas da Uefa Euro 2008, o que foi previamente confirmado por DI SALVO et al. (2007) (0,5\%), ou com maiores valores percentuais (7\%,8\%) (BARROS et al., 2007; RAMPININI et al., 2007) do que os do presente estudo. 


\section{CONCLUSÃO}

Os resultados do presente estudo permitem concluir que: i) futebolistas da elite europeia percorreram $10232 \pm 852$ m nos jogos da Uefa Euro 2008, excluindo-se goleiros; ii) meio-campistas percorreram maior distância ( $0894 \pm$ $648 \mathrm{~m})$, seguidos por laterais ( $10274 \pm 694 \mathrm{~m})$, atacantes (I $0108 \pm 624 \mathrm{~m})$, zagueiros (9498 $\pm 592 \mathrm{~m}$ ) e goleiros (4I $98 \pm 610 \mathrm{~m})$; iii) a distância percorrida no $\mathrm{I}^{\circ}$ tempo das partidas (4907 $\pm 20 \mathrm{~lm}$ ) foi maior do que a percorrida no $2^{\circ}$ tempo (4890 $\pm 238 \mathrm{~m})$. Por fim, esses são direcionamentos que contribuem para a preparação dos futebolistas, pois se subentende que treinem em concordância com o modelo competitivo da modalidade para alcançar altos níveis de performance.

\section{Competitive model of distance covered by soccer players in Uefa Euro 2008}

ABSTRACT: The aim of this study focuses on knowing the competitive model of distance covered by soccer players in the Uefa Euro 2008, in the positions of the game, times and the total distance covered during the matches. It was analyzed all matches from 16 teams, totaling 31 games of which involved 460 soccer players. Subsequently, produced descriptive and inferential information. The main results show that: i) European soccer players elite covered $10232 \pm 852 \mathrm{~m}$; ii) a midfielders (I $0894 \pm 648 \mathrm{~m}$ ) greater distance covered, followed by external defenders (10274 $\pm 694 \mathrm{~m})$, forwards (10108 $\pm 624 \mathrm{~m})$, central defenders (9498 $\pm 592 \mathrm{~m}$ ) and goalkeepers (4198 $\pm 610 \mathrm{~m})$; iii) the average of covered distance at first half $(4907 \pm 20 \mathrm{~lm}$ ) for matches was higher than the second half $(4890 \pm 238 \mathrm{~m})$.

KEY WORDS: Competitive model group; distance covered; soccer.

\section{Modelo competitivo de la distancia recorrida por futbolistas en Uefa Euro 2008}

RESUMEN: El objetivo de este estudio se centra en conocer el modelo competitivo de la distancia recorrida por futbolistas en Uefa Euro 2008, por las posiciones de juego, tiempos y la distancia total recorrida durante los partidos. Se analizaron todos los juegos de 16 selecciones, totalizando 31 juegos que participaron 460 futbolistas. Posteriormente, fueran producidas informaciones descriptivas e inferencia. Los principales resultados indican que: i) futbolistas de la elite Europea recorrerán $10232 \pm 852 \mathrm{~m}$; ii) centro-campistas ( $10894 \pm 648 \mathrm{~m})$ recorrerán mayor distancia, seguido por laterales (10274 $\pm 694 \mathrm{~m})$, delanteros (10108 $\pm 624 \mathrm{~m})$, defensores $(9498 \pm 592 \mathrm{~m})$ y porteros $(4198 \pm 610 \mathrm{~m})$; iii) la media distancia recorrida en $101^{\circ}$ tiempo $(4907 \pm 201 \mathrm{~m})$ de los juegos fue superior a $2^{\circ}$ tiempo (4890 $\left.\pm 238 \mathrm{~m}\right)$.

PALABRAS CLAVES: Modelos competitivos; distancia recorrida; fútbol. 


\section{REFERÊNCIAS}

BANGSBO, J.; MOHR, M.; KRUSTRUP, P. Physical and metabolic demands of training and match-play in the elite football player. Journal of Sports Science, v. 24, n. 7, p. 665-674, 2006.

BANGSBO, J.; NORREGAARD, L.; THORSO, F. Activity profile of competition soccer. Canadian Journal Sports Science, n. 16, p. I10-116, 1991.

BARROS, R. M. L.; MISUTA, M. S.; MENEZES, R. P.; FIGUEROA, P. J.; MOURA, F. A.; CUNHA, S. A.; ANIDO, R.; LEITE, N. J. Analysis of the distances covered by first division Brazilian soccer players obtained with an automatic tracking method. Journal of Sports Science and Medicine, n. 6, p. 233-242, 2007.

BRADLEY, P. S.; SHELDON, W.; WOOSTER, B.; OLSEN, P.; BOANAS, P.; KRUSTRUP, P. High-intensity running in English FA Premier League soccer matches. Journal of Sports Sciences, v. 27, p. 2, p. 159-168, 2009.

BRASIL. Ministério da Saúde. Conselho Nacional de Saúde - CNS. Resolução n. 196 de 10 de outubro de 1996. Disponível em: <www.conselho.saude.gov.br/docs/Resolucoes/ Resol96de96.doc>. Acesso em: 2 dez. 2008.

BRAZ, T. V. Modelos competitivos da distância percorrida por futebolistas profissionais: uma breve revisão. Revista Brasileira de Futebol, v. 2, p. 2-12, 2009.

CAIXINHA, P. F.; SAMPAIO, J.; MIL-HOMENS, P. V. Variação dos valores da distância percorrida e da velocidade de deslocamento em sessões de treino e em competições de futebolistas juniores. Revista Portuguesa de Ciências do Desporto, v. 4, n. I, p. 7-16, 2004.

DI SALVO, V.; BARON, R.; CARDINALE, M. Time motion analysis of elite footballers in European cup competitions. Journal of Sports Science and Medicine, p. 14- I5, 2007. Suppl. 10.

DI SALVO, V.; BARON, R.; TSCHAN, H.; MONTERO, F. J.; BACHL, N.; PIGOZZI, F. Performance characteristics according to playing position in elite soccer. International Journal of Sports Medicine, v. 28, n. 3, p. 222-227, 2007.

DI SALVO, V.; BENITO, P. J.; CALDERÓN, F. J.; DI SALVO, M.; PIGOZZI, F. Activity profile of elite goalkeepers during football match-play. Journal of Sports Medicine and Physical Fitness, v. 48, p. $443-446,2008$.

DI SALVO, V.; GREGSON, W.; ATKINSON, G.; TORDOFF P.; DRUST, B. Analysis of high intensity activity in premier league soccer. International Journal of Sports Medicine, v. 30, p. 205-212, 2009.

GARGANTA, J. A análise da performance nos jogos desportivos: revisão acerca da análise do jogo. Revista Portuguesa de Ciência do Desporto, v. I , n. I, p. 57-64, 200 I. 
HELGERUD, J.; ENGEN, L. C.; WISLOFF, U.; HOFF, J. Aerobic endurance training improves soccer performance. Medicine Science and Sports Exercise, v. 33, n. II, p. 1925-1931, 2001.

HENNIG, E. M.; BRIEHLE, R. Game analysis by GPS satellite tracking of soccer players. In: XI CONGRESS OF THE CANADIAN SOCIETY FOR BIOMECHANICS. Montreal, p. 44, 2000.

IMPELLIZZERI, F. M.; MARCORA, S. M.; CASTAGNA, C.; REILLY, T.; SASSI, A.; IAIA, F. M.; RAMPININI, E. Physiological and performance effects of generic versus specific aerobic training in soccer players. International Journal of Sports Medicine, n. 27, p. 483-492, 2006.

MEDEIROS FILHO, E. S.; HADDAD, J. P. A. Futebol profissional: campo cheio não ajuda a ganhar jogo. Revista Brasileira de Ciência do Esporte, v. 30, n. I, p. I23-135, 2008.

MISUTA, M. S. Rastreamento automático de trajetórias de jogadores de futebol por videogrametria. Dissertação (Mestrado em Educação Física) - Universidade Estadual de Campinas, Campinas, 2005.

MIYAGI, O.; OHASHI, J.; KITAGAWA, K. Motion characteristics of an elite soccer player during a game. Journal of Sports Science, n. 17, p. 816, 1999.

MOHR, M.; KRUSTRUP, P.; BANGSBO, J. Match performance of high-standard soccer players with special reference to development of fatigue. Journal of Sports Science, n. 2I, p. 519-528, 2003.

NEVILL, A.; ATKINSON, G.; HUGHES, M. Twenty-five years of sport performance research in the Journal of Sports Sciences. Journal of Sports Science, v. 26, n. 4, p. 4I 3-426, 2008.

ODETOYINBO, K.; WOOSTER, B.; LANE, A. The effect of a succession of matches on the activity profiles of professional soccer players. Journal of Sports Science and Medicine, p. 16-17, 2007. Suppl. 10.

PLATONOV, V. N. Tratado geral de treinamento desportivo. São Paulo: Phorte Editora, 2008.

RAMPININI, E.; COUTTS, A. J.; CASTAGNA, C.; SASSI, R.; IMPELLIZZERI, F. M. Variation in top level soccer match performance. International Journal of Sports Medicine, n. 28, p. $1018-1024,2007$.

RANDERS, M. B.; JENSEN, J. M.; KRUSTRUP, P. Comparison of activity profile during matches in Danish and Swedish premier league and matches in Nordic royal league tournament. Journal of Sports Science and Medicine, n. 16, 2007. Suppl. 10.

REILLY, T. An ergonomics model of the soccer training process. Journal of Sports Science, v. 23, n. 6, p. 56I-572, 2005. 
REILLY, T.; GILBOURNE, D. Science and football: a review of applied research in the football codes. Journal of Sports Science, n. 21, p. 693-705, 2003.

REILLY, T.; THOMAS, V. A motion analysis of work rate in different positional roles in professional football match-play. Journal Human Movement Studies, n. 2, p. 87-97, 1976.

RIENZI, E.; DRUST, B.; REILLY, T.; CARTER, J. E.; MARTIN, A. Investigation of anthropometric and work-rate profiles of elite South American International soccer players. Journal of Sports Medicine and Physical Fitness, v. 40, n. 2, p. 162-169, 2000.

SHEPARD, R. J. Biology and medicine of soccer: an update. Journal of Sports Science, n. I7, p. 757-786, 1999.

STRUDWICK, T.; REILLY, T. Work-rate profiles of elite Premier League football players. Insight: The FA Coaches Association Journal, v. 4, n. 2, p. 28-29, 2001.

THATCHER, R.; BATTERHAM, A. M. Development and validation of a sport-specific exercise protocol for elite youth soccer players. Journal of Sports Medicine and Physical Fitness, v. 44, n. I, p. 15-22, 2004.

ZUBILLAGA, A.; GOROSPE, G.; MENDO, A.H.; VILLASEÑNR, A. B. Match analysis of 2005-06 Champions League Final with Amisco system. Journal of Sports Science and Medicine, p. 20, 2007. Suppl. 10.

Recebido: 20 jan. 2009

Aprovado: 13 fev. 2010

Endereço para correspondência

Tiago Volpi Braz

Rua Cirilo Silva, 106 - Bairro dos Funcionários

Poços de Caldas-MG

CEP 3770I-306 